\title{
An event-related potential study of the revelation effect
}

\author{
NAZANIN AZIMIAN-FARIDANI and EDWARD L. WILDING \\ Cardiff University, Cardiff, Wales
}

\begin{abstract}
Event-related potentials (ERPs) were recorded during a verbal recognition memory task in order to investigate whether changes in familiarity are part of the explanation for the revelation effect. For half of the test words, participants solved an anagram prior to making the old/new recognition judgment. A revelation effect was obtained: When test words were preceded by the anagram task, a higher probability of an old response was associated with the items than was otherwise the case. The ERPs recorded timelocked to the onset of the test words were separated according to old/new status and the presence/absence of the anagram task. The ERP index of familiarity was of lower amplitude for both old and new items that were preceded by the anagram task. These findings are consistent with the view that part of the explanation for the revelation effect is a reduction in the familiarity of the critical test items.
\end{abstract}

Completing an interpolated task immediately prior to making an old/new recognition memory judgment can result in performance changes on the recognition task when compared with the situation where no task intervenes between successive old/new judgments. This change manifests itself as an increased likelihood of an old response to both old (previously studied) and new test items.

This finding is known as the revelation effect (Watkins \& Peynircioğlu, 1990), because the initial experiments in which the effect was obtained involved revealing a word to which a recognition judgment was then required. For example, in one experiment by Watkins and Peynircioğlu, half of the test items were words to which a recognition judgment was required, while the remainder were anagrams that participants solved before making an old/new judgment on the anagram solution. The likelihood of an old response for words presented as anagrams was increased compared with those that were not (hereafter the revealed and the control conditions).

Revelation effects where the interpolated tasks involved anagram solutions have been reported by other researchers (Niewiadomski \& Hockley, 2001; Peynircioğlu \& Tekcan, 1993; Westerman \& Greene, 1996), and comparable behavioral outcomes have been obtained with tasks involving reading inverted or rotated words (Peynircioğlu \& Tekcan, 1993; Watkins \& Peynircioğlu, 1990), revealing items letter by letter (LeCompte, 1995; Peynircioğlu \& Tekcan, 1993; Watkins \& Peynircioğlu, 1990), and identifying perceptually degraded stimuli (Luo, 1993). Westerman and Greene $(1996,1998)$ demonstrated that the ef-

We thank Mariam Dzulkifli, Jane Herron, Caren Rotello, and two anonymous reviewers for comments on an earlier draft of this manuscript. This research was supported by the BBSRC. Correspondence concerning this article should be addressed to N. Azimian-Faridani, School of Psychology, Cardiff University, Cardiff CF10 3AT, Wales (e-mail: nazanin@cardiff.ac.uk). fect occurs when the anagram solution is not the word subjected to the subsequent recognition memory judgment. The effect also occurs when mathematical calculations constitute the interpolated task (Niewiadomski \& Hockley, 2001).

From the perspective of dual-process accounts of recognition memory, the weight of evidence favors the view that the revelation effect is linked to responses made on the basis of familiarity rather than recollection (Cameron \& Hockley, 2000; Landau, 2001; LeCompte, 1995; Westerman, 2000). Two principal explanations have been given for this link. The first is that revelation changes the familiarity of test items. For example, Westerman and Greene (1998) appealed to global matching models of recognition memory, according to which the likelihood of an old response increases as the level of activation generated by a retrieval cue increases (Gillund \& Shiffrin, 1984; Hintzman, 1988; Murdock, 1993). Westerman and Greene (1998) proposed that the relative increase in activation (hence, the degree of familiarity) for revealed versus control items is a consequence of confusing activation generated during completion of the interpolated task with that generated by the ensuing item to which a recognition judgment is required.

The second explanation is that completing the interpolated task results in the adoption of a more liberal decision criterion in the revealed than in the control condition, the outcome being an increase in the likelihood of an old response (Hockley \& Niewiadomski, 2001; Niewiadomski \& Hockley, 2001; Verde \& Rotello, 2003, 2004). One proposal is that this more liberal disposition occurs because completing the interpolated task dislodges from working memory the criterion that is maintained when successive old/new judgments are made (Hockley \& Niewiadomski, 2001; Niewiadomski \& Hockley, 2001).

As rows 1 and 2 of Figure 1 illustrate, these competing accounts can both explain the revelation effect, and they 
are difficult to separate because they make similar predictions (Hicks \& Marsh, 1998). If familiarity is characterized as a signal detection process (Yonelinas, 1997), then equivalent levels of discrimination combined with apparent changes in criterion can be achieved by shifting the criterion (upper row of Figure 1: from A to B) or by shifting the familiarity of test items while holding the criterion constant (middle row of Figure 1: criterion placement in this row for $\mathrm{A}$ is equivalent to that for $\mathrm{B}$ in the upper row).

Row 3 of Figure 1 illustrates another possible explanation for the revelation effect that Hicks and Marsh (1998) have proposed. They attempted to adjudicate between the familiarity- and criterion-change accounts using the two-alternative forced choice (2AFC) paradigm, the logic being that in this procedure response criterion is effectively removed if it is assumed that test responses are made only on the basis of an assessment of the relative familiarity of each test pair (Egan, 1975; Green \& Swets, 1966; Macmillan \& Creelman, 1991). Thus the presence of the effect in this paradigm would suggest that completion of the interpolated task influences the familiarity of revealed items.

Hicks and Marsh (1998) obtained what they termed an "anti-revelation" effect: Completing the interpolated task (anagram solution) and then a $2 \mathrm{AFC}$ distinction between the solution and another word increased the likelihood of selecting the word that had not been revealed. These results were obtained when test pairs comprised two old words as well as when two unstudied words were paired. The findings are consistent with the view that completing an intervening task reduces the familiarity of the subsequent item. If this is correct, then, as Hicks and Marsh noted and Figure 1 illustrates, the revelation effect can be explained by a reduction in item familiarityperhaps due to a decrease in the signal:noise ratio because of the anagram solution requirement - in combination with the adoption of a more liberal response criterion. The second component of this account - the criterion changeis necessary in order to explain the revelation effect if a familiarity decrement is part of the explanation, as a decrement to familiarity in the absence of criterion change (placement A of row 3 in Figure 1) would reduce the likelihood of an old response in the revealed condition.

Whether the account of the revelation effect in the 2AFC paradigm applies to single-item recognition remains to be determined; the experiment reported here was designed to distinguish between the foregoing accounts of the revelation effect when only single items were presented at test. Mirroring the approach adopted by Hicks and Marsh (1998), our experiment was designed to hold response criterion constant, which was accomplished by employing an event-related potential (ERP) index of familiarity as a dependent variable. The way in which this index was employed to monitor changes in familiarity is described below.

ERPs have been employed extensively to investigate the processes engaged during recognition memory tasks. The most common approach involves analysis of ERP

1. Liberal Criterion Shift

2. Increment to Familiarity

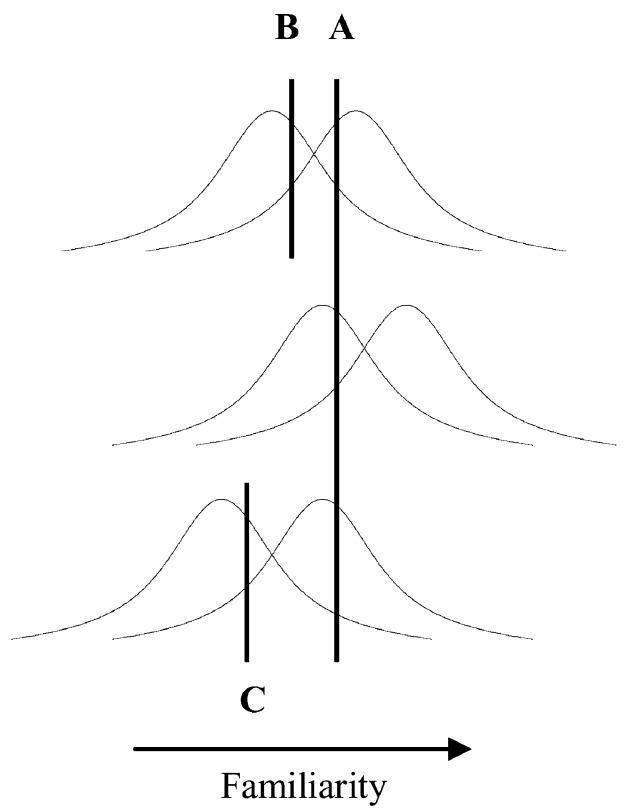

Figure 1. Three ways in which changes in familiarity and/or changes in response criterion can explain the revelation effect. Relative to the levels of familiarity depicted for old and new items in row 1 , the overall levels in rows 2 and 3 are higher (farther to the right) and lower (farther to the left), respectively. Relative to the overall levels of familiarity in each case, the placement of criterion $C$ in row 3 is equivalent to the placements of $B$ and $A$ in rows 1 and 2, respectively. 
old/new effects - the differences between the electrical activity evoked by old and new test items to which correct recognition judgments have been made. In some recent studies, an ERP old/new effect that likely indexes item familiarity has been identified (Curran, 1999, 2000; Curran \& Cleary, 2003; Nessler, Mecklinger, \& Penney, 2001; Penney, Mecklinger, \& Nessler, 2001; Rugg et al., 1998; Tsivilis, Otten, \& Rugg, 2001). The effect consists of a relatively greater positivity in the ERPs that are elicited by old compared with new words attracting correct judgments. The greater relative positivity is evident from approximately $300-500 \mathrm{msec}$ poststimulus at electrodes over the anterior scalp and is assumed to reflect the fact that these words are more familiar than new words by virtue of their presentation at study.

Arguably the strongest evidence that this old/new effect is a correlate of familiarity comes from a recent study by Curran (2000). Participants studied words in singular or plural forms (e.g., frogs, lake) and were tested with studied words (e.g., frogs), new words (e.g., capitol), and lures where the plurality was the opposite of that at study (e.g., lakes). Presumably, in the absence of recollection of study material, lures should seem as familiar as studied words and should attract more old responses than should new words. This pattern of behavioral results was obtained, and furthermore the putative indices of familiarity were equivalent for old responses to old words and to lures, thereby providing strong evidence linking this modulation of the electrical record to familiarity.

Our manner of employing the electrophysiological index of familiarity to investigate the processes responsible for the revelation effect stems from the fact that ERPs recorded during the test phases of a recognition task can be separated along two dimensions - the old/new status of test items and the old/new responses to those items. The focus here is on separation according to old/ new status only, since separating items solely according to this dimension provides a contrast that is blind to response criterion, ${ }^{1}$ in much the same way as Hicks and Marsh's (1998) use of the 2AFC paradigm.

Thus, contrasts across revealed and control conditions between ERPs separated only according to old/new status (repetition effects) offer a means to distinguish among the three explanations for the revelation effect illustrated in Figure 1. If the revelation effect can be explained solely in terms of a criterion change (Hockley \& Niewiadomski, 2001; Niewiadomski \& Hockley, 2001), then the amplitudes of the ERPs elicited by old and new items in the 300- to 500-msec time window at anterior electrode sites should not vary according to whether an interpolated task precedes old/new judgments. If the mean amplitudes of the index of familiarity do vary according to the presence/absence of the interpolated task, however, then changes in familiarity likely play a role in the revelation effect. An increase in the mean amplitudes for test items preceded by an interpolated task would suggest that the effect is due to an increase in item familiarity. The alternative outcome-a relative reduction in mean amplitudes- would indicate that part of an explanation for the revelation effect is a decrease in the familiarity of test items (Hicks \& Marsh, 1998).

\section{METHOD}

\section{Participants}

Thirty-three undergraduates ( 15 female, age range for entire group 18-28, all native English speakers) from Cardiff University were paid $£ 5 / \mathrm{h}$ for participating. All were right-handed and reported normal or corrected-to-normal vision. Data from 12 participants ( 9 female) were discarded prior to analysis. Data were lost for 1 participant due to a technical failure. The remainder contributed insufficient trials to the critical conditions following artifact rejection (see below). All participants gave informed consent.

\section{Materials and Design}

Stimuli were 480 low-frequency words (4-9 letters in length, frequency 1-7 per million: Kučera \& Francis, 1967). Three task lists comprising all 480 words were created by rotating words so that across lists each word was encountered as an anagram, an old word, and a new word. Words in each list were divided randomly into two equal groups, creating two study-test cycles, each containing 80 study words and 240 test words (equal numbers of anagrams, old words, and new words). Half of the old and new test words were preceded by an anagram. All stimuli were presented centrally in uppercase letters on a PC monitor. Words were presented in white against a black background, anagrams in blue. Stimuli subtended maximum visual angles of $0.6^{\circ}$ (vertical) and $2.2^{\circ}$ (horizontal). Anagrams were formed using a transposition rule: The first letter of each word was the last letter of the corresponding anagram, and positioning of the subsequent letters was determined by placing each letter alternately on the left, then on the right of the preceding letter. Hence CORGI becomes OGIRC. Stimuli appeared in one study-test cycle only.

\section{Procedure}

Participants were fitted with an electrode cap before the experiment (see below). They were seated in a sound-attenuated booth and faced a monitor with their thumbs on response keys. They were informed that all words encountered in the study phases would be re-presented in the test phases and that there would be two study-test cycles. A practice session preceded the experiment, and a break of 5 min occurred between cycles.

Study phase. Trials began with a hash mark (\#), which was displayed for $500 \mathrm{msec}$ and followed by a blank screen $(250 \mathrm{msec})$. The study word was then displayed for $300 \mathrm{msec}$. Participants indicated via keypress whether the first and last letters were in alphabetical order. The next trial began 1,000 msec after the participant responded.

Test phase. Stimuli were presented in a highlighted white box frame in the center of the monitor. Test words were presented for $300 \mathrm{msec}$, and the next trial began $1,000 \mathrm{msec}$ after the participant responded. Half of the trials commenced with an anagram. The rule for solving anagrams was given to participants before each test phase. Participants spoke aloud the anagram solution and pressed a key to continue the task. Participants were asked to spend no more than a minute on each anagram and, when unable to find a solution, to press any key to continue. The anagram remained on the screen until a response was made and was followed by a blank screen $(1,000 \mathrm{msec})$ before the test word was shown. Trials commencing with either an anagram or a test word were interspersed randomly and in a different order for each participant. Participants were told that the anagram solution would always differ from the subsequent word to which a recognition memory judgment would be required. The hands used for judgments at study and test were balanced across participants. 
The ongoing electroencephalogram (EEG) was recorded from 27 silver/silver chloride electrodes, 25 housed in an elastic cap. As Figure 2 shows, the sites were located at midline $(\mathrm{Fz}, \mathrm{Cz}, \mathrm{Pz})$ and at left- and right-hemisphere locations (FP1/FP2, F7/F8, F5/F6, F3/F4, T3/T4, C5/C6, C3/C4, T5/T6, P5/P6, P3/P4, O1/O2; Jasper, 1958). Additional electrodes were placed on the mastoid processes. Vertical and horizontal electro-ocular activity (EOG) was recorded from electrodes placed above and below the left eye and over the outer canthi of the two eyes, respectively. EEG was recorded continuously at $166 \mathrm{~Hz}$ with $\mathrm{Cz}$ as reference, and was re-referenced off-line to a linked mastoid reference ${ }^{2}$ into baseline-corrected epochs of 1,536 msec (102 msec prestimulus baseline). EEG and EOG were recorded with a bandwidth of $0.03-40 \mathrm{~Hz}(-3 \mathrm{~dB})$. Trials containing eye-blinks were submitted to a correction algorithm where appropriate. Trials with A/D saturation or baseline drift exceeding $\pm 80 \mu \mathrm{V}$ were also rejected. Participants were excluded if they did not contribute to each condition at least 16 trials in which a correct response was made. The averaged ERPs were subjected to a seven-point binomially weighted smoothing filter before analysis.

\section{RESULTS}

\section{Behavioral Data}

Table 1 shows the mean probabilities of old responses to old and new words in the revealed and control condi- tions. An analysis of variance (ANOVA), including the factors of condition (revealed vs. control) and word status (old vs. new), revealed main effects only, reflecting the fact that the likelihood of an old response was greater for old than for new words $[F(1,12)=219.40, p<.001]$ and greater in the revealed than in the control condition $[F(1,20)=6.56, p<.025]$. We calculated $c$ as a measure of criterion placement, and a subsequent analysis revealed that participants were relatively more liberal in the revealed than in the control condition [0.06 vs. 0.18 ; $t(20)=2.56, p<.025]$.

\section{ERP Data}

Averaged ERPs were formed for old and new words in the revealed and control conditions. Mean trial numbers were 55 and 54 for old and new words, respectively, in the revealed condition, and 58 and 57 in the control condition. The ERP index of familiarity was analyzed by computing mean amplitudes averaged across five electrode sites: FP1, FP2, F3, F4, and Fz, as shown in Figure 2. The waveforms in this figure are the averaged ERPs collapsed across these locations, separated ac-

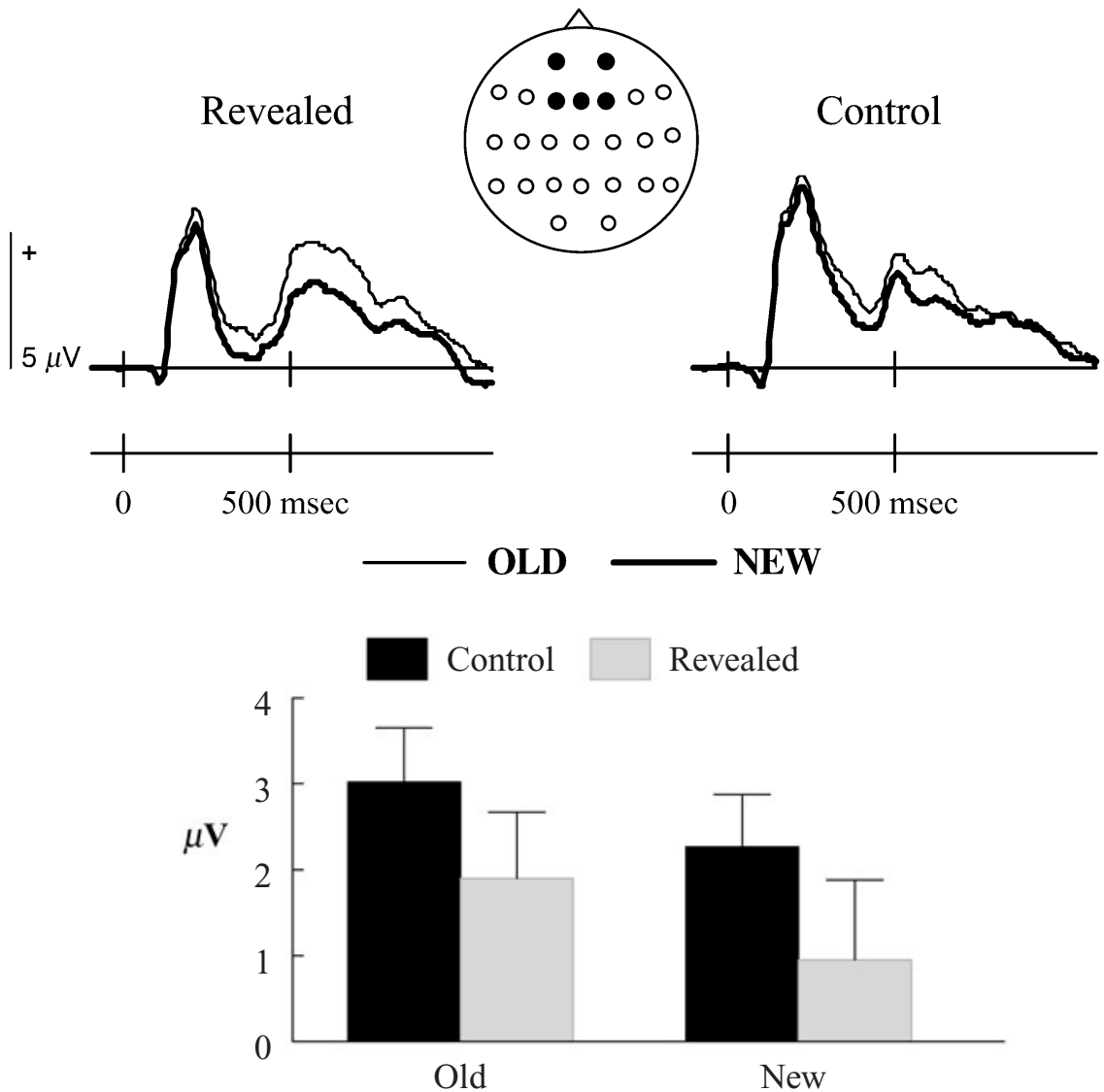

Figure 2. Grand average ERPs evoked by old and new words in the revealed and control conditions. The depiction of scalp locations (center-top of figure) shows the sites across which the ERP waveforms are collapsed. The lower part of the figure shows the mean amplitude measures and associated standard errors for the ERPs associated with old and new items over the 300- to 500-msec time window. 
Table 1

Mean Probabilities of Old Responses to Old and New Words in Revealed and Control Conditions

\begin{tabular}{llllll}
\hline & \multicolumn{4}{c}{ Status } \\
\cline { 2 - 4 } \cline { 5 - 6 } Condition & $M$ & & & \multicolumn{2}{c}{ New } \\
\cline { 2 - 6 } \cline { 5 - 6 } & .12 & & .32 & .12 \\
Revealed & .64 & .13 & & .27 & .13 \\
\hline
\end{tabular}

cording to condition and old/new status. In both conditions, from $300 \mathrm{msec}$ onward, the ERPs elicited by old test words are relatively more positive-going than those elicited by new words. This relative positivity continues for approximately 400-600 msec.

The critical ANOVA is that of the ERP repetition effects over the 300 - to 500 -msec time window. This analysis included the factors of condition (revealed/control) and word status (old/new) and yielded main effects of both factors only [condition, $F(1,20)=5.48, p<.05$; status, $F(1,20)=6.00, p<.025]$. As Figure 2 shows, these results come about because the mean amplitudes associated with old words are greater than those associated with new words, and the mean amplitudes in general are greater in the control than in the revealed condition. A second ANOVA on the amplitude data from the 500to 700-msec epoch also included factors of location and status. This analysis yielded a main effect of status only $[F(1,20)=5.94, p<.025]$, reflecting the relatively greater positivity associated with old than with new test words. The absence of an effect involving condition over this epoch indicates that the differences due to condition were restricted to the time period in which the ERP index of familiarity has been identified in previous studies.

\section{DISCUSSION}

A revelation effect was obtained: Participants were more likely to make an "old" response to a revealed word than to a control word. We conducted the ERP analyses to determine whether changes in familiarity form part of an explanation for this pattern of behavioral data. To this end, the critical analysis was restricted to mean amplitudes over a scalp region and time period in which an electrophysiological index of familiarity has been identified in previous studies (Curran, 1999, 2000; Rugg et al., 1998). In keeping with existing findings, the ERPs associated with old words were reliably more positivegoing than those associated with new words. Critically, the mean amplitudes for old and new words in the control condition were also reliably more positive-going than those for their counterparts in the revealed condition. To the extent that greater relative positivity is a reflection of greater familiarity, these findings provide strong evidence in support of the view that a decrement to familiarity is part of the explanation for the revelation effect.

The data therefore do not support proposals that an increment in the familiarity of test items is the reason for the revelation effect (Westerman \& Greene, 1998) or that the effect can be accounted for solely in terms of changes in response criterion (Hockley \& Niewiadomski, 2001; Niewiadomski \& Hockley, 2001; Verde \& Rotello, 2003, 2004). The data are, however, consistent with a decrementto-familiarity account. Hicks and Marsh (1998) offered this account on the basis of findings in a 2 AFC paradigm, and in those experiments the revealed word formed one of the pair between which participants adjudicated on each trial. In the present study, single words were presented on each test trial, and the anagram solution on revealed trials differed from the subsequent word to which old/new recognition judgments were made. The fact that the ERP data are consistent with a decrement-to-familiarity account suggests that the explanation offered by Hicks and Marsh is not peculiar to the 2AFC paradigm, nor does it apply only when the anagram solution is immediately subject to an old/new recognition judgment.

In combination with the findings of Hicks and Marsh (1998), therefore, these electrophysiological data make a compelling case that a decrement in familiarity is one consequence of completing an intervening task prior to making an old/new judgment. As noted in the introduction, if this result is indeed part of the explanation for the revelation effect, then a necessary assumption is that participants also adopt a more liberal response criterion on revealed than on control trials (see Figure 1). The present findings do not speak to the questions of why this occurs or what task characteristics enable and/or encourage changes in response criterion. (For one possible answer to these questions, see Hicks \& Marsh, 1998).

One noteworthy point, however, is that changes in familiarity and response criterion may come about because of distinct components of the typical revelation paradigm. This possibility is supported by the recent findings of Verde and Rotello (2003, 2004), who present receiveroperating characteristic data consistent with the view that while a liberal criterion shift is a common aspect of the revelation effect, a shift in familiarity occurs in some circumstances but not in others. The findings reported here suggest that acquiring ERPs alongside behavioral measures can be a fruitful means of investigating further questions of this type.

\section{REFERENCES}

Cameron, T. E., \& Hockley, W. E. (2000). The revelation effect for item and associative recognition: Familiarity versus recollection. Memory \& Cognition, 28, 176-183.

CURRAN, T. (1999). The electrophysiology of incidental and intentional retrieval: ERP old/new effects in lexical decision and recognition memory. Neuropsychologia, 37, 771-785.

Curran, T. (2000). Brain potentials of recollection and familiarity. Memory \& Cognition, 28, 923-938.

CuRran, T., \& Cleary, A. M. (2003). Using ERPs to dissociate recollection from familiarity in picture recognition. Cognitive Brain Research, 15, 191-205.

EGAN, J. P. (1975). Signal detection theory and ROC analysis. New York: Academic Press.

Gillund, G., \& Shiffrin, R. M. (1984). A retrieval model for both recognition and recall. Psychological Review, 91, 1-67. 
Green, D. M., \& Swets, J. A. (1966). Signal detection theory and psychophysics. New York: Wiley.

HiCKS, J. L., \& MARSH, R. L. (1998). A decrement-to-familiarity interpretation of the revelation effect from forced-choice tests of recognition memory. Journal of Experimental Psychology: Learning, Memory, \& Cognition, 24, 1105-1120.

HintZMAN, D. L. (1988). Judgments of frequency and recognition memory in a multiple-trace memory model. Psychological Review, 95, 528-551.

HOCKLEY, W. E., \& NiEWIADOMSKI, M. W. (2001). Interrupting recognition memory: Tests of a criterion-change account of the revelation effect. Memory \& Cognition, 29, 1176-1184.

JASPER, H. A. (1958). The ten-twenty system of the International Federation. Electroencephalography \& Clinical Neurophysiology, 10, 371-375.

KuČERA, H., \& FrAnCIS, W. N. (1967). Computational analysis of presentday American English. Providence, RI: Brown University Press.

Landau, J. D. (2001). Altering the balance of recollection and familiarity influences the revelation effect. American Journal of Psychology, 114, 125-137.

LECompte, D. C. (1995). Recollective experience in the revelation effect: Separating the contributions of recollection and familiarity. Memory \& Cognition, 23, 324-334.

LuO, C. R. (1993). Enhanced feeling of recognition: Effects of identifying and manipulating test items on recognition memory. Journal of Experimental Psychology: Learning, Memory, \& Cognition, 19, 405413.

Macmillan, N. A., \& Creelman, C. D. (1991). Detection theory: A user's guide. New York: Cambridge University Press.

Murdock, B. B. (1993). TODAM2: A model for storage and retrieval of item, associative, and serial-order information. Psychological Review, 100, 183-203.

Nessler, D., Mecklinger, A., \& Penney, T. B. (2001). Event related brain potentials and illusory memories: The effects of differential encoding. Cognitive Brain Research, 10, 283-301.

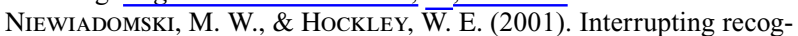
nition memory: Tests of familiarity-based accounts of the revelation effect. Memory \& Cognition, 29, 1130-1138.

Penney, T. B., Mecklinger, A., \& Nessler, D. (2001). Repetition related ERP effects in a visual object target detection task. Cognitive Brain Research, 10, 239-250.

PEYNIRCIOǦLU, Z. F., \& TEKCAN, A. I. (1993). Revelation effect: Effort or priming does not create the sense of familiarity. Journal of Experimental Psychology: Learning, Memory, \& Cognition, 19, 382-388.

RugG, M. D., Mark, R. E., Walla, P., SchloerscheidT, A. M., Birch,
C. S., \& Allan, K. (1998). Dissociation of the neural correlates of implicit and explicit memory. Nature, 392, 595-598.

Tsivilis, D., OtTEn, L. J., \& RugG, M. D. (2001). Context effects on the neural correlates of recognition memory: An electrophysiological study. Neuron, 31, 497-505.

Verde, M. F., \& ROTELlo, C. M. (2003). Does familiarity change in the revelation effect? Journal of Experimental Psychology: Learning, Memory, \& Cognition, 29, 739-746.

Verde, M. F., \& Rotello, C. M. (2004). ROC curves show that the revelation effect is not a single phenomenon. Psychonomic Bulletin \& Review, 11, 560-566.

WATKIns, M. J., \& PEYNIRCIOǦLU, Z. F. (1990). The revelation effect: When disguising test items induces recognition. Journal of Experimental Psychology: Learning, Memory, \& Cognition, 16, 1012-1020.

WESTERMAN, D. L. (2000). Recollection-based recognition eliminates the revelation effect in memory. Memory \& Cognition, 28, 167-175.

Westerman, D. L., \& Greene, R. L. (1996). On the generality of the revelation effect. Journal of Experimental Psychology: Learning, Memory, \& Cognition, 22, 1147-1153.

Westerman, D. L., \& GREene, R. L. (1998). The revelation that the revelation effect is not due to revelation. Journal of Experimental Psychology: Learning, Memory, \& Cognition, 24, 377-386.

WindmanN, S., Urbach, T. P., \& Kutas, M. (2002). Cognitive and neural mechanisms of decision biases in recognition memory. Cerebral Cortex, 12, 808-817.

Yonelinas, A. P. (1997). Recognition memory ROCs for item and associative information: The contribution of recollection and familiarity. Memory \& Cognition, 25, 747-763.

\section{NOTES}

1. There is no good evidence to date that ERPs are sensitive to changes in criterion. While Windmann, Urbach, and Kutas (2002) reported effects of changes in criterion on the ERP index of familiarity, their betweenparticipants design confounded changes in familiarity with changes in criterion placement.

2. Some studies in which electrophysiological indices of familiarity have been examined have employed an average reference (e.g., Curran, 1999, 2000). In these studies, as well as in those employing a linked mastoid reference (e.g., Rugg et al., 1998; Tsivilis et al., 2001), analyses of ERP effects linked to familiarity have focused on fronto-central electrode locations.

(Manuscript received June 27, 2003; revision accepted for publication October 23, 2003.) 